\title{
VISUALIZATIONS
}

\section{Visualising cities' international scientific collaboration: a spatial scientometric approach based on Scopus data}

\author{
György Csomós \\ University of Debrecen, \\ Department of Civil Engineering \\ E-mail: csomos@eng.unideb.hu
}

Spatial scientometrics deals with measuring, analysing, and visualising science with spatial components (Gao 2014). The first studies discussing the spatial distribution of science were published in the 1970s (Frenken et al. 2009); however, in tandem with the rapid globalisation of science, spatial scientometrics has attracted more attention only recently (Bornmann et al. 2011). One reason for this is that, in the past few decades, research and scientific production have gradually lost their individual characteristics and have significantly internationalised. Measuring and visualising international scientific collaboration patterns of countries, cities, and organisations is an important feature of spatial scientometrics.

In this study, I visualise cities' international scientific collaboration patterns based on two different approaches. Scientometric data are retrieved from the Scopus database. After scrutinising the whole database, I assigned journal articles to the cities to which corresponding authors were affiliated (for more details, see Csomós, 2017). These cities were located in 232 countries and, in total, there were 52,577 affiliated organisations. In the analysis, only the cities that had at least 1,000 journal articles indexed by Scopus over the period 1986 to 2015 were included. These criteria were fulfilled by 2,194 cities. Scopus' search results analyser function made it possible to examine the characteristics of cities' international collaboration, that is, to identify the most important collaborating country (i.e. authors affiliated with that country) for a given city (i.e. authors affiliated with that city). For example, the 240,822 articles produced in Washington, D.C. were co-written with authors from more than 160 countries: 9,537 articles were co-written by authors from the United Kingdom, which emerges as the most important collaborator, 8,420 articles were co-written by authors from Canada, and 7,467, by authors from Germany. Similarly, I defined the most important collaborators of all cities. Figure 1 and Figure 2 show the ten most important collaborating countries with two different approaches.

Regional Statistics, Vol. 7. No.1. 2017: 225-228; DOI: 10.15196/RS0712 
Figure 1.

The most important collaborators (countries) of cities worldwide

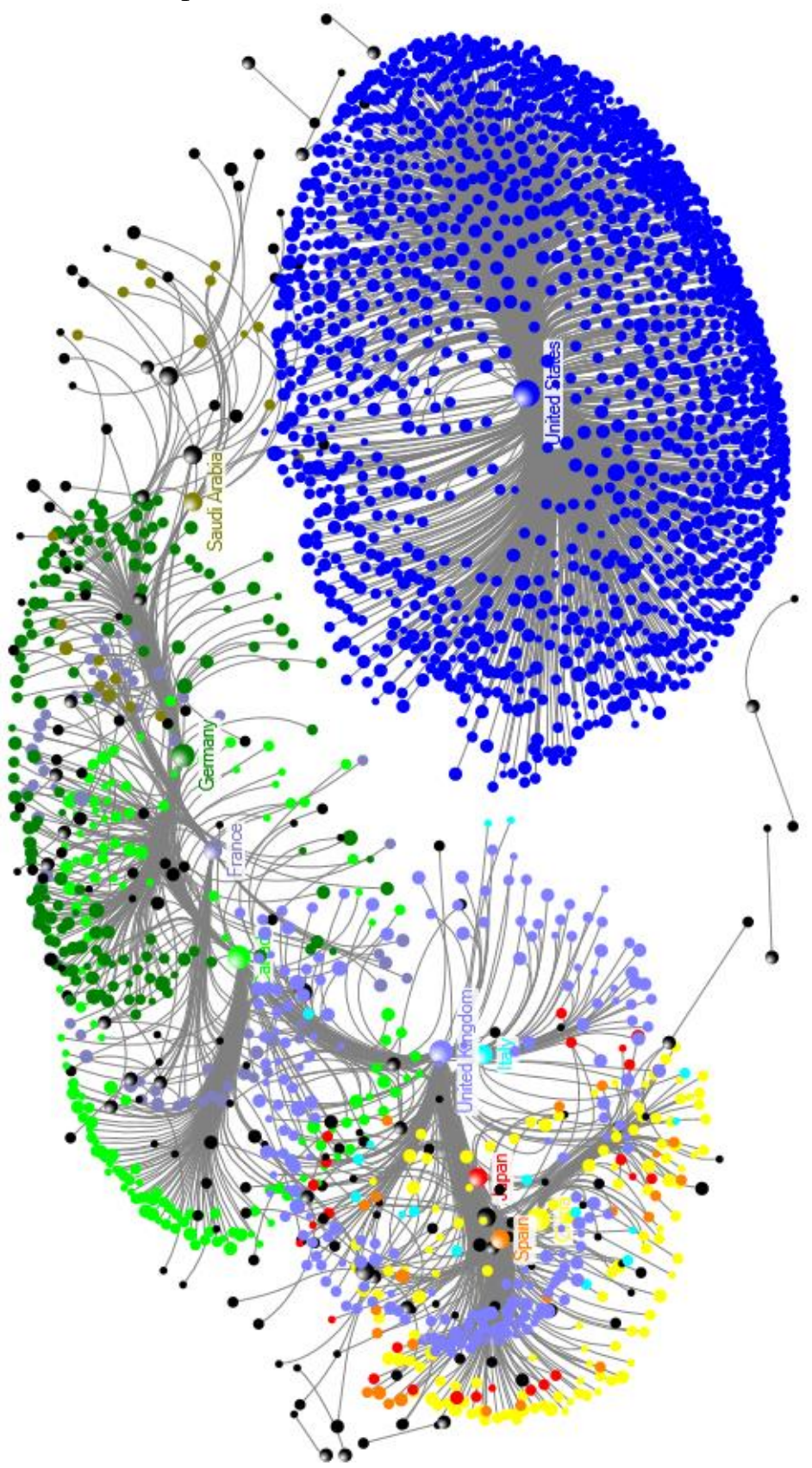

Regional Statistics, Vol. 7. No.1. 2017: 225-228; DOI: 10.15196/RS0712 
Figure 2.

The most important collaborators (countries) of cities, not including the United States

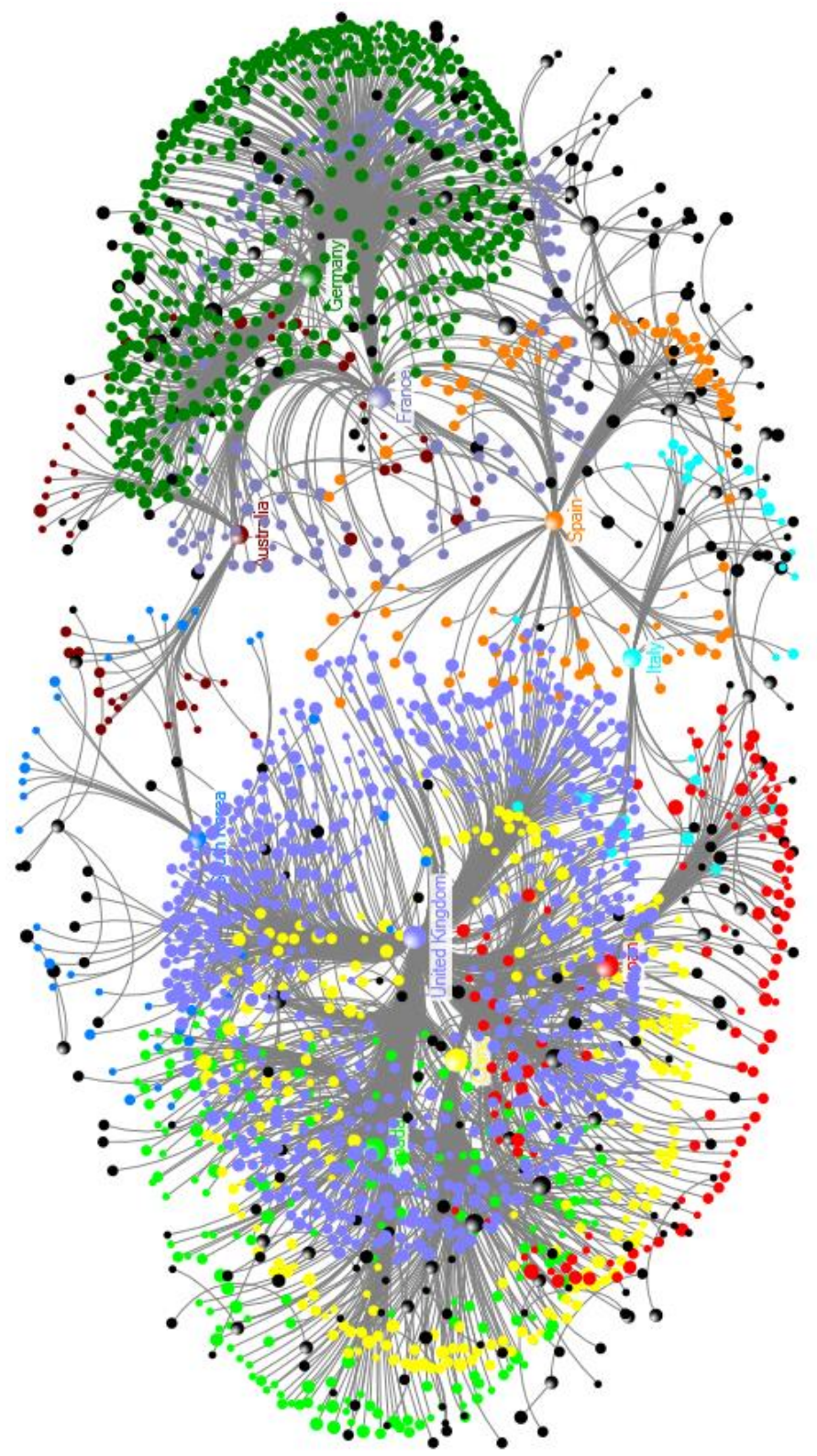

1) The most important collaborating countries for cities worldwide. The hegemony of the United States in science has been observed by many researchers (see, for example, Paasi 2005, Pan et al. 2012). Figure 1 shows that for 1,261 cities

Regional Statistics, Vol. 7. No.1. 2017: 225-228; DOI: 10.15196/RS0712 
(57.5 per cent of all cities, or 73.5 per cent if we exclude 478 US cities), the United States is indeed the most important collaborator. The United Kingdom is ranked second, being the most important collaborator for 9 per cent of all cities, followed by Canada, the most important collaborator for 160 cities, with only five outside the United States. In addition to these three English-speaking countries, only Germany (153 cities) and China (121 cities) are considered as important international collaborators. Ten countries (i.e. the United States, the United Kingdom, Canada, Germany, China, France, Japan, Spain, Saudi Arabia, and Italy) are the most important collaborators for 93.3 percent of all cities (Figure 1), making the role of other countries marginal.

2) The most important collaborating countries for cities, not including the United States. In order to examine cities' international collaborations in a more realistic way, the distorting effect generated by the United States' hegemony has to be isolated. To this end, I excluded the country from the sample. Figure 2 shows that, without the United States, the United Kingdom becomes the most important collaborator in the world. However, the United Kingdom, the second-ranked Germany, and the third-ranked China are, all together, the top collaborators for roughly the same number of cities (1,280 cities) as the United States (1,261 cities, Figure 1). This reinforces the unique position of the United States in international science. The ten top-ranked countries (i.e. the United Kingdom, Germany, China, Canada, France, Japan, Spain, Australia, South Korea, and Italy) are the most important collaborators for 89.2 per cent of all cities.

Software: NodeXL

\section{Acknowledgements}

This paper is supported by the János Bolyai Research Scholarship of the Hungarian Academy of Sciences.

\section{REFERENCES}

BORnMANN, L.-LEYDESDORFF, L.-WALCH-SOLIMENA, C.-ETTL, C. (2011): Mapping excellence in the geography of science: An approach based on Scopus data Journal of Informetrics 5 (4): 537-546.

Csomós, GY. (2017): A spatial scientometric analysis of the publication output of cities worldwide Journal of Informetrics 11 (4): 976-988.

Frenken, K.-Hardeman, S.-HoEkman, J. (2009): Spatial scientometrics: Towards a cumulative research program Journal of Informetrics 3 (3): 222-232.

GAO, S. (2014): Towards a Frontier of Spatial Scientometric Studies arXiv:1406.2793.

PAASI, A. (2005): Globalisation, academic capitalism, and the uneven geographies of international journal publishing spaces Environment and Planning A 37 (5): 769-789.

PAN, K. R.-KASKI, K.-FORTUNATO, S. (2012): World citation and collaboration networks: uncovering the role of geography in science Scientific Reports 2, Article number: 902.

Regional Statistics, Vol. 7. No.1. 2017: 225-228; DOI: 10.15196/RS0712 